This item was submitted to Loughborough's Research Repository by the author.

Items in Figshare are protected by copyright, with all rights reserved, unless otherwise indicated.

\title{
Modelling foot-and-mouth disease virus dynamics in oral epithelium to help identify the determinants of lysis
}

PLEASE CITE THE PUBLISHED VERSION

http://dx.doi.org/10.1007/s11538-010-9576-6

\section{PUBLISHER}

(C) Springer

VERSION

AM (Accepted Manuscript)

\section{PUBLISHER STATEMENT}

This work is made available according to the conditions of the Creative Commons Attribution-NonCommercialNoDerivatives 4.0 International (CC BY-NC-ND 4.0) licence. Full details of this licence are available at: https://creativecommons.org/licenses/by-nc-nd/4.0/

\section{LICENCE}

CC BY-NC-ND 4.0

\section{REPOSITORY RECORD}

Schley, David, John P. Ward, and Zhidong Zhang. 2019. "Modelling Foot-and-mouth Disease Virus Dynamics in Oral Epithelium to Help Identify the Determinants of Lysis". figshare. https://hdl.handle.net/2134/19388. 


\title{
Modelling foot-and-mouth disease virus dynamics in oral epithelium to help identify the determinants of lysis \\ David Schley ${ }^{\mathrm{a}, *}$, John Ward ${ }^{\mathrm{b}}$ \& Zhidong Zhang ${ }^{\mathrm{a}}$ \\ ${ }^{a}$ Institute for Animal Health, Pirbright Laboratory, Ash Road, Pirbright, Surrey, GU24 ONF, UK. \\ ${ }^{b}$ Department of Mathematical Sciences, Loughborough University, Leicestershire, LE11 3TU, UK.
}

\begin{abstract}
Foot-and-mouth disease virus (FMDV) causes an economically important disease of clovenhoofed livestock; of interest here is the difference in lytic behaviour that is observed in bovine epithelium. On the skin around the feet and tongue the virus rapidly replicates, killing cells and resulting in growing lesions, before eventually being cleared by the immune response. In contrast there is usually minimal lysis in the soft palate, but virus may persist in tissue long after the animal has recovered from the disease. Persistence of virus has important implications for disease control, while identifying the determinant of lysis in epithelium is potentially important for the development of prophylactics. To help identify which of the differences between oral and pharyngeal epithelium are responsible for such dramatically divergent FMDV dynamics a simple model has been developed, in which virus concentration is made explicit to allow the lytic behaviour of cells to be fully considered. Results suggest that localised structuring of what are fundamentally similar cells can induce a bifurcation in the behaviour of the system, explicitly whether infection can be sustained or results mutual extinction, although parameter estimates indicate that more complex factors may be involved in maintaining viral persistence, or that there are as yet unquantified differences between the intrinsic properties of cells in these regions.
\end{abstract}

Keywords: Foot-and-Mouth Disease Virus; Epithelium; Lysis; Model.

\section{Introduction}

Foot-and-mouth disease (FMD) is a highly infectious disease of cloven hoofed animals which has a severe impact on their welfare and productivity. The disease is of significant social and economic importance both in regions of the world where it is endemic and in those countries considered disease-free by the OIE (World Organisation for Animal Health). It is considered serious enough to justify the mandatory implementation of stringent control measures including mass culling and/or vaccination.

\section{$1.1 \quad$ Foot-and-mouth disease virus}

FMD virus (FMDV) is transmitted by direct contact, fomites and through the air, but primarily infects epithelial (skin) cells. Progression of the disease differs somewhat amongst species, but in cattle infection results in fever with vesicular lesions around the feet and in the mouth (Alexandersen et al., 2003): Figure 1 shows the rapid progression of the disease in the tongue, highlighted by the sharp boundary of ulcerated areas. Healthy adult animals usually recover in a matter of weeks but often with severely reduced productivity, and the mortality in young animals may be considerable, including a high level of foetal mortality.

The future development of effective control strategies requires an improved understanding of the dynamics of FMDV, especially for the development of effective vaccines. Significant progress continues to be made examining numerous aspects of the virus's interaction with, and the reaction from, host cells, especially at a molecular level (Saiz et al., 2002), and modelling offers the opportunity to integrate disparate results and offer an insight into the dynamic processes of the system that cannot always be captured experimentally.

\subsection{Bovine oral epithelium}

Skin is formed of stratified squamous epithelium, consisting of flattened layers of epithelial cells. The actual cells occupy approximately $95 \%$ of epithelium by volume (Moore 1987), with the remainder of the space being fluid filled extracellular matrix (ECM). Skin is not uniform but consist of a number of layers, through which cells progress from when they are first formed (through cell division at the bottom) to the surface (where they are shed)). These layers are usually classified as follows: the stratum basale (basal layer) consists of those cells connected to the blood vessels, and are the only ones that proliferate (divide).

\footnotetext{
${ }^{*}$ Corresponding author. E-mail address: David.Schley@bbsrc.ac.uk (David Schley)
} 

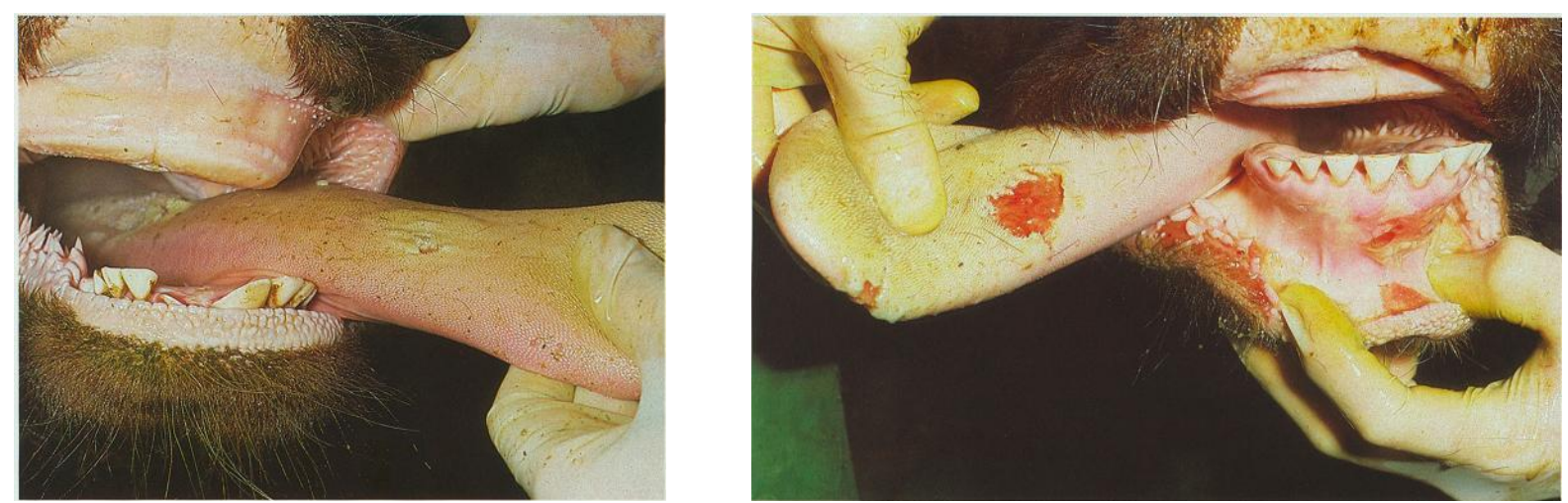

Figure 1: Cattle tongue with: (a) 1 day old vesicle (the rupture shown was a result of the tongue being withdrawn from the mouth); (b) 2 day old naturally ruptured vesicle. Reproduced with permission from Anon (1986).

As these mature they differentiate to the stratum spinosium (spinos layer) which forms the majority of living tissue.

Most skin, including the tongue and inter-digital area and coronary band of the feet of cloven hoofed animals has an additional cornified layer, consisting of a stratum granulosum and a stratum corneum. Differentiating cells enter these layer as they die, as can be seen by the loss of nuclei, and form a tough keratinised surface to the skin. On the tongue the living cells (basal and spinos layers) alone are approximately $230 \mu \mathrm{m}$ thick, formed, we estimate, of approximately 20 cells. The pharynx (dorsal soft palate and nasopharynx) of cattle consists only of these two cell layer types and is approximately $90 \mu \mathrm{m}$ thick, which we estimate as being formed by a depth of approximately 9 cells. Soft palate epithelium is therefore quite specialised and different from other regions, with the nucleus maintained in terminally differentiating cell. In mice basal cells make up 39.6 $\pm 6.9 \%$ of cells (Potten et al., 2002a) but epithelium is only $46.8-54.9 \mu \mathrm{m}$ thick (Potten et al., 2002b) so it is unclear if this can be applied to cattle.

It is our understanding that the actual cells in each region are fundamentally the same - as has been noted by their similarity when grown in culture. It is possible that cells within the palate exhibit a higher rate of proliferation than those on the tongue: for human epithelial cells proliferation of the epidermis has been found to be slower than for epithelium from the mouth (Gibbs and Ponec, 2000) although no comparison of soft palate and tongue epithelium was given; and patterns of loricrin expression indicate that squamous differentiation in internal epithelia of the upper alimentary tract in rodents and higher mammals differ remarkably( Hohl et al., 1993). It has been shown that non-keratinised cells have higher mitotic rate, at least in monkeys (Rowat and Squier, 1986), but this may not be a causal link since these cells are found in different locations, and proliferation has also been correlated with epithelium thickness (Rowat and Squier, 1986), and In-vivo observations of cattle have found that $\alpha_{v} \beta_{6}$ receptors, associated with FMDV uptake, appear "more numerous" in areas of the tongue where lesions occur (Monaghan et al., 2005). As yet, however, there have been no in-vitro experiments and so results could be related to cell differentiation rather than region.

\subsection{FMDV infection}

Following infection, virus in the epithelium of the tongue and feet replicates rapidly culminating in lysis (cell death resulting in the release of virions); eventually the immune response clears the virus and symptoms gradually disappear (Grubman and Baxt, 2004). In contrast, few cytopathological changes are observed in pharyngeal epithelium during the acute stage of infection even when the cells from this region harboured significant levels of viral RNA (Zhang and Alexandersen, 2004).

Virus is predominantly detected in the spinos and basal cells, although lower levels have also been shown to be present in cornified cells (Zhang and Kitching, 2001; Durand et al., 2008); the cell structure of the latter is very different with little if any cellular protein synthesis. 


\subsubsection{Cell lysis}

Previous studies on distribution of viral RNA levels in bovine tissues during the acute stage of infection with FMDV UKG 2001 showed that virus load in the soft palate is much lower than that in tongue (Zhang and Alexanderson et al 2004). When epithelial cells isolated from bovine soft palate were infected with FMDV UKG34 for 24 hours, epithelial cell survival rate was about 95\%, while in infected parts of the tongue this could be as low as $10 \%$.

It has been postulated that this difference is more likely to be the result of changes in the virus at the site of persistence as opposed to cell differences (Zhang and Kitching, 2001), since the cells concerned are all fundamentally the same, although so far no mechanism has been proposed. Although there are numerous pressures on viruses (Krakauer and Komarova, 2003), currently there is no evidence that the intrinsic replication rate differs between cells.

\subsubsection{Viral persistence}

In ruminants FMDV is able to persist, at low levels, beyond the periods of acute infection or clinical disease and recovery (Zhang and Alexandersen, 2004; Grubman and Baxt, 2004).

This only occurs in palate tissue but may be related to the associated structure, such as the presence of lymphocites, rather than the epithelium cells themselves. Understanding the mechanisms of persistence is important, however, since although transmission of infection by domestic "carrier" animals has so far not been recorded (Parida et al., 2005), unlike wild buffalo (Dawe et al., 1994), there is at least a theoretical risk that they could initiate new outbreaks, especially with developments in the use of vaccines (Barnett and Cox, 1999; Kitching et al., 2007).

\subsection{Models of infection}

In contrast to a significant body of work modelling the epidemiology of FMD (see for example Keeling, 2005, and references therein), focusing on the transmission of disease between farms, there are almost no models of within-host dynamics, with the exception of the whole animal model developed by Quan et al (Quan, 2005; Howey et al., 2008). Here we investigate the first of a planned family of models exploring the dynamics FMDV infected epithelium. Specifically, we focus on the dichotomy observed in oral bovine epithelium in order to gain insights into which factors in the system are most important in the progression of the disease.

At present the reasons for such dramatically different in virus behaviour between the palate and tongue are unclear, although a number of hypotheses have been proposed (See sections 1.2 and 1.3). In this paper we therefore seek to identify the simplest possible biologically plausible mechanism capable of driving such qualitative differences, and pay particular attention to those factors for which there exists empirical evidence of a difference between tongue and palate epithelium. Predominant amongst these is tissue thickness - see sections 1.2. Our aim is to help guide the focus of future experimental research in this area, and with this goal in mind we consider the repudiation of assumptions that a specific biological factor has a significant role in this process as valuable as the identification of those which potentially do.

\section{Methods}

\subsection{Epithelium model}

In the absence of virus we wish to consider the simplest reasonable model of cell tissue stasis. All cell types are modelled as one group, although only the basal layer group will proliferate. It is therefore assumed that the ratio of cell types remains approximately constant throughout, something which is considered reasonable since the lesions observed in infected tissue are usually highly localised and very deep (Alexandersen et al., 2003). We consider only living cells (basal and spynosum) as these are the only ones of interest when considering FMDV infection on a short time scale. The model for distinct tissues regions is therefore fundamentally the same, but with a different interpretation for cell removal: in the palate, cells will be sloughed off; on the tongue, cells die and differentiate to the granulosum layer.

Letting $C$ be the total number of living cells within a layer of epithelial tissue and defining $r$ as the proliferation rate of cells and $\gamma$ as the rate at which live cells are removed from the system (either by 


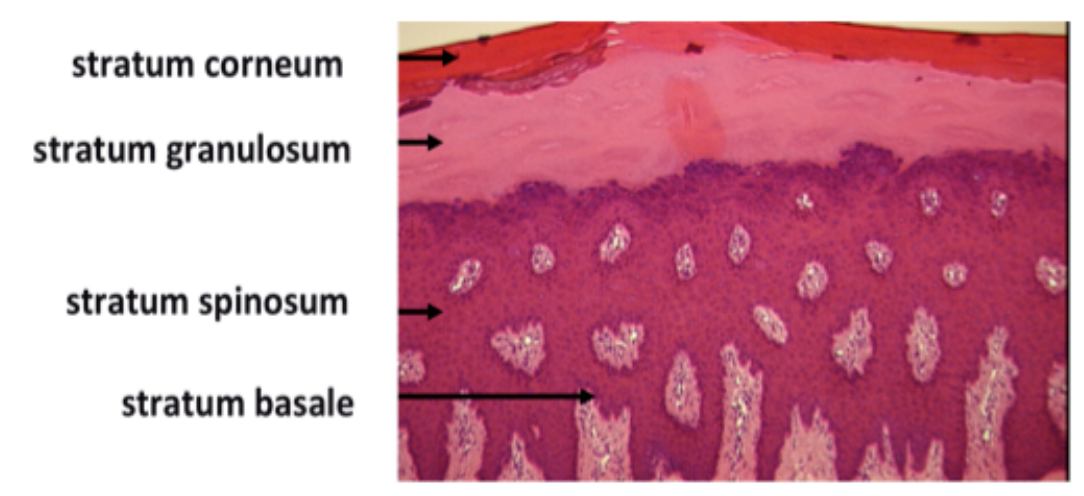

(a)

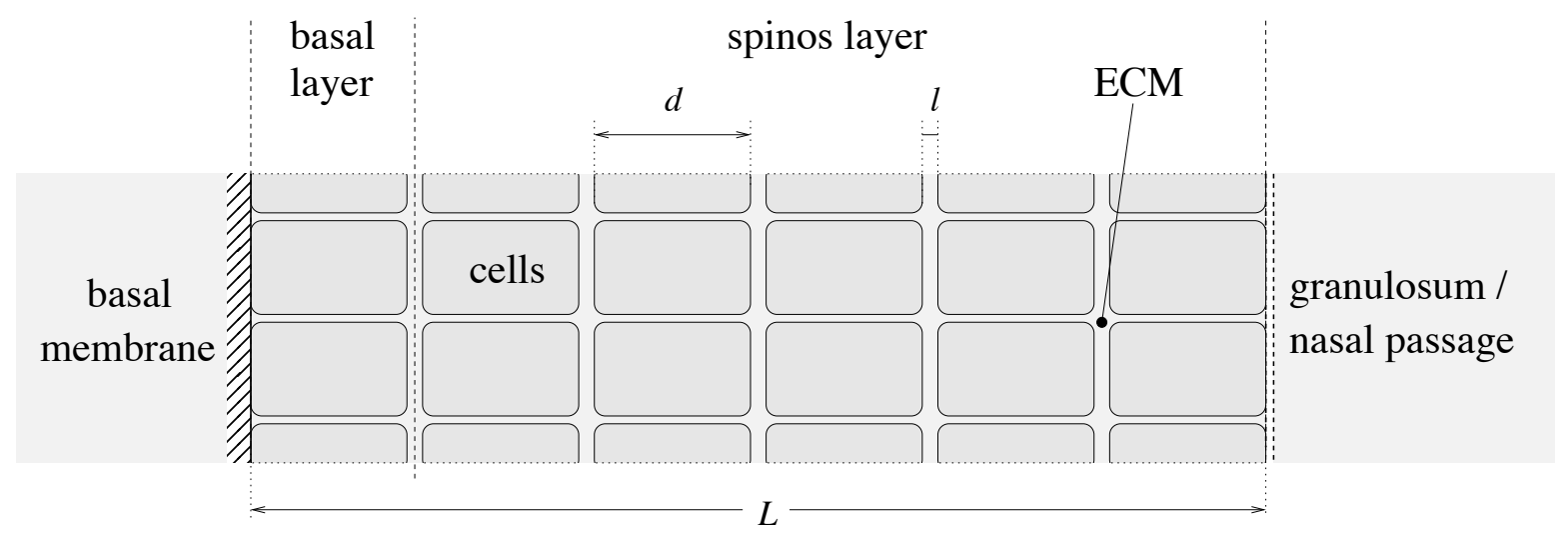

(b)

Figure 2: (a) Cross section microscopic image of bovine tongue epithelium, displaying distinct layers of epithelial tissue above the basal membrane. (b) Schematic of the model skin structure. The distance of $L$ of $C_{0}$ cells consist of and $C_{0}-1$ gaps. Though the cells and gaps illustrated here are uniform across the skin, this need not be the case in the model with $d$ and $l$ being the mean values of the cell diameter and gap respectively. Virus can exists within cells and within the ECM, passing between them through infection (uptake by) and lysis of (release from ) cells.

keratinisation or by sloughing) we set:

$$
\frac{d}{d t}(C)=r C\left(1-\frac{C}{K}\right)-\gamma C
$$

where $K$ is some natural limiting factor prevent overproduction of cells. This expression is the wellknown logistic equation and is the simplest model that possess the following features on growth and removal. The first term on the right-hand side describes growth in the skin layer, whilst the second is removal of live cells, via keratinisation in the tongue or by sloughing in the palette. We expect in a damaged skin state, i.e. when $C$ is small, that the few remaining healthy skin cells will be required to divide to promote healing and we assume $d C / d t \approx(r-\gamma) C$ with $r-\gamma>0$ (this is a modelling constraint). Furthermore, we expect that the propensity of these cells to be keratinised or sloughed will be small initially, but will increase as the cell thickness increases; the simplest rate function that describes this process is " $-\gamma C$ ". Finally, this model exhibits a unique, globally attractive equilibrium

$$
C_{0}=K(1-\gamma / r),
$$

for $r>\gamma$, which represents the number of cells in undamaged, viral free, healthy skin. In what follows we consider only $C_{0}>1$ since all epithelial tissues extends well beyond the basal layer. 


\subsubsection{Skin structure parameters}

In this Section we relate measurable parameters to some more detailed components in the skin structure. Data for macroscopic features such as the number of cell layers (i.e. the cell depth $C_{0}$ ) are readily available through microscopic analysis of skin sections, but relevant aspects of the skin that are more difficult to quantify such as skin thickness $L$ and mean gap between cells $(l)$; see Figure 2 . There is no evidence to suggest that mean epithelial cell size differs between the palate and tongue and we assume that these cells have the same mean diameter $d$. These quantities are related as follows

$$
L \approx C_{0} d+\left(C_{0}-1\right) l .
$$

which state simply that the skin thickness is equal to the total thickness of cells $\left(C_{0} d\right)$ and total gap between them $\left(\left(C_{0}-1\right) l\right)$. It is useful for the discussion in future sections to introduce the ECM gap fraction $\omega$, which is defined to be the mean fraction of space between the cell layers across the skin depth, so that the total cell thickness is $(1-\omega) L$ and the total ECM thickness is $\omega L$. It follows that the skin thickness is approximately $L \approx C_{0} d /(1-\omega)$, the mean gap between cells is approximated by $l \approx \omega C_{0} d /(1-\omega)\left(C_{0}-1\right)$ and, in particular,

$$
\frac{l}{L} \approx \frac{\omega}{\left(C_{0}-1\right)} .
$$

A further useful quantity in what follows is $E_{0}=L / d$, which is the total number of cells that can fit into a space of length $L$ with no ECM, hence $C<E_{0}$. Using (2) we get

$$
E_{0}=\frac{C_{0}}{1-\omega}=K \frac{1-\gamma / r}{1-\omega} .
$$

As we will in the first instance model intra- and extra-cellular virus particle concentration, we need to track the extracellular space volume; this is calculated in terms of $\epsilon$, which is the number of cells that can fit in the extracellular space, namely

$$
\epsilon \approx E_{0}-C \text {. }
$$

This space expands as cells are killed but will be reduce as the skin recovers.

\subsection{FDMV infected epithelium model}

Let $V$ be the concentration of virions per cell, and $V_{\epsilon}$ be the concentration of virions per cell sized volume of ECM space. That is to say, across the skin thickness, the total intracellular viral load is $C V$ and the total extracellular viral load is $\epsilon V_{\epsilon}$. Picornaviruses, including FMDV, are able to kill cells through apoptosis (Peng et al., 2004; Jin et al., 2007), and this appears to be correlated with viral load (Girard et al.,1999). Shortly after infection only low amounts of parental infectious material can be identified: this is the so called eclipse phase during which genome replication has been initiated but progeny viruses are not yet released. Following this there is a maturation phase, when viral material accumulates exponentially in the cell or surrounding medium, after which lysis usually occurs. It is therefore reasonable to define the rate at which cells are killed due to viral infection by $\phi f(V)$, where $f(V)=1$ so that $\phi$ is the maximum cell death rate. In addition to $f(0)=0$ we expect the lytic response of cells to be monotonically increasing with $V$, so that $f^{\prime}(V) \geq 0$ and therefore $f(V) \rightarrow 1$ as $V \rightarrow \infty$, although the exact response function is unknown. We postulate that this response is a result of intracellular resource being exhausted, although the model and mechanisms described are independent of any such assumption.

For analytic work we consider the generalised form of the the lytic response function $f(V)$, within the constraints detailed above, i.e.

$$
f(0)=0, \max _{V \geq 0} f(V)=1 \text { and } f^{\prime}(V) \geq 0 \text { for all } V \geq 0 .
$$

For numerical simulations we will, in the absence of any data, use a smooth response function of the form:

$$
f(V)=\frac{V^{n}}{k^{n}+V^{n}}, \quad k, n>0,
$$

where $k$ is the viral concentration at which half the maximum lytic response rate is achieved (see section 4 for further details). 
Cellular virus load $(V C)$ changes in response both to changes in virus concentration and cell number, as well as uptake by cells of virus from the surrounding ECM. The amount of virus in the ECM $\left(V_{\epsilon} \epsilon\right)$ is a result of lytic virus release from (dead) cells, the uptake of virions by (live) cells and the removal of virions from the ECM by other means.

The growth of virus within cells is assumed to follow a logistic pattern, i.e. the virus will grow exponentially when it is at low levels, due to there being plenty of cellular material to make new virus, until it reaches a threshold concentration, $\kappa$, at which the net proliferation is zero due to exhaustion of this material. Intracellular virus is lost when a cell is removed by keritinisation or sloughing (at a rate $\gamma V C$ ) and is released into the ECM when a cell lyses due to virus (at a rate $\phi f(V) V C$ ). Extracellular virus uptake by cells is assumed to be at a rate proportional to the virus concentration and cell number (namely $\mu V_{\epsilon} C$ ): we assume that the uptake rate $\mu$ encapsulates the affinity of virion attachment to the cell membrane and diffusion in the ECM. Washout of virus occurs at the basal lemma and skin surface (particularly in the case of the palate), and we assume that this occurs at a rate proportional to it number of virions, namely $\delta V_{\epsilon} C$. Combining these assumptions, the full system of equations is given by:

$$
\begin{aligned}
\frac{d}{d t}(C) & =r C\left(1-\frac{C}{K}\right)-\gamma C-\phi f(V) C, \\
\frac{d}{d t}(V C) & =\rho V C\left(1-\frac{V}{\kappa}\right)-\gamma V C-\phi f(V) V C+\mu V_{\epsilon} C, \\
\frac{d}{d t}\left(V_{\epsilon} \epsilon\right) & =\phi f(V) V C-\mu V_{\epsilon} C-\delta V_{\epsilon} \epsilon,
\end{aligned}
$$

where all parameters are positive, the values of which discussed in section 2.5. We note that the last two equations are statements for the rates of change of the total number of virions, rather than explicitly describing the rates of change of concentration. We note further, that $V$ is not bounded above by $\kappa$ as more virus may be obtained through uptake, but net proliferation of virus is limited by this level.

\subsection{Timescales}

The system operates over a number of different time-scales. Cell proliferation is of the order of one day, while turn-over rate is much longer at between one and three weeks. Viral replication is much more rapid, measurable in minutes, with resultant lysis possible in a matter of hours. Within the ECM we expect viral diffusion to be very high, so that uptake and washout take much less than a minute. This is made explicit by the parameter estimates given in Tables $1-3$.

The model only considers innate cell immunity and is only valid for the duration prior to the immune response. Significant titres of circulating antibodies (which we take as an indicator of the immune response being active) can be detected around three to five days after the first appearance of clinical signs, attain high level around two to four days later (Alexandersen et al., 2003). We therefore assume that circulatory immunity may becomes important after the second day, at which time we expect this model (which does not explicitly include the immune response) to ceases to be valid.

The time-scale of interest is that covering the dynamics of the cell population during the first two to three days post infection. The extracellular viral dynamics are much more rapid than this: something we make use of in section 2.4 to simplify the system. We may also neglect $\gamma$ over this period although in what follows the algebra is equally tractable if it is included; the predominant requirement would be that $r>\gamma$ as opposed to $r>0$. (Note, however, that $\gamma$ cannot be absorbed by a rescaling of $r$ alone.)

\subsection{Reduced model}

We consider the ECM to be in quasi-equilibrium so $\frac{d}{d t}\left(V_{\epsilon} \epsilon\right) \approx 0$, yielding:

$$
\mu V_{\epsilon}=\frac{\phi f(V) V C}{C+\theta\left(E_{0}-C\right)}, \quad \text { where } \quad \theta=\delta / \mu \text {. }
$$

This expression can be derived on the assumptions that $\rho, \phi$ and $\gamma$ are very much smaller than $\mu$ or $\delta\left(E_{0} / C_{0}-1\right)$ or both. That is, if the rates of viral uptake and washout occur on much faster timescales than virus growth and cellular response. Here, a formal analysis of the system applying these assumptions would make explicit a very rapid initial timescale (see the discussion on initial conditions below) in which 
the virus particle concentrations in cells and ECM equilibrates; following this, the $\frac{d}{d t}\left(V_{\epsilon} \epsilon\right)$ term will be very much smaller than each of the terms on the right-hand side of (9), hence (10) results.

Expanding the derivatve on the left hand side of (8) and substituting in (7) and (10) gives, after some rearrangement:

$$
\dot{V}=V\left[\rho(1-V / \kappa)-r(1-C / K)+\frac{\phi f(V) C}{C(1-\theta)+\theta E_{0}}\right] .
$$

We may absorb $\gamma$ by rescaling:

$$
\hat{r}=r-\gamma, \hat{\rho}=\rho-\gamma, \hat{\kappa}=\frac{\rho-\gamma}{\rho} \kappa
$$

substituting (12) and $C_{0}=K(r-\gamma) / r$ from (2) into (7) and (11) we derive our model equations:

$$
\begin{aligned}
\dot{C} & =C\left[\hat{r}\left(1-C / C_{0}\right)-\phi f(V)\right], \\
\dot{V} & =V\left[\hat{\rho}(1-V / \hat{\kappa})-\hat{r}\left(1-C / C_{0}\right)+\frac{\phi f(V) V C}{C(1-\theta)+\theta E_{0}}\right] .
\end{aligned}
$$

Since $\gamma \leq \Gamma$, the turnover rate of cells at the surface, and $\Gamma \ll r, \rho$ (see Tables $1-3$ for explicit details), however, it is reasonable to approximate

$$
\hat{r} \approx r, \hat{\rho} \approx \rho, \hat{\kappa} \approx \kappa
$$

and this is done in what follows. Full results may be recovered at any time by considering the full expressions (12) instead of the approximations (14) in the equations below.

The simplicity of the system, and the direct biological relevance of parameters, mean that we consider it counter-productive to non-dimensionalize prior to analysis, although the natural scaling of the system is to consider factors of $C_{0}$ and $\kappa$ for cells and virions respectively and to study it on an intrinsic time-scale of $r^{-1}$.

\subsubsection{Initial conditions}

To close the system we need to impose initial conditions on $V$ and $C$. It is expected that the infection begins with FMD virus being present only in the ECM where they will soon attach and infiltrate cells. For the full model, we would therefore impose

$$
C(0)=C_{0}, \quad V(0)=0, \quad V_{\epsilon}(0)=v_{0},
$$

where $C_{0}$ is the healthy skin thickness and $v_{0}$ is the initial concentration of virus in the ECM. The quasi-steady equilibrium results from the assumption that in a very small initial timescale the process of viral uptake and washout dominate the dynamics of the system so that $C \sim C_{0}$, i.e. negligible time for virus to reproduce and cells to start dying, and thus $d V / d t \sim \mu V_{\epsilon}$ and $d V_{\epsilon} / d t \sim-\left(\mu+\delta \epsilon / C_{0}\right) V_{\epsilon}$; hence, over this timescale, $V_{\epsilon} \rightarrow 0$ and $V \rightarrow v_{0} /(1+\theta)$ in an exponential fashion. The relevant modification of the initial conditions for the quasi-steady model lysis are thus:

$$
C(0)=C_{0}, \quad V(0)=\frac{v_{0}}{1+\theta\left(E_{0} / C_{0}-1\right)} .
$$

\subsection{Parameter estimates}

Parameter estimates, and their sources, are given in Table 1. FMD viral loads of $10^{8}$ RNA molecules/ $\mu l$ have been recorded, equivalent to $10^{5}$ molecules / cell (Garica-Arriaza et al., 2004), with initial growth in culture of $10^{4}$ to $10^{7}$ virions/ml within $24 \mathrm{~h}$ (de Boer \& Bachrach, 1961) occurring through (assumed uninhibited) exponential growth. These results are consistent with indirect estimates based upon measurements of plaque forming units per cell (PFU/cell) and the ratio of particles to PFU; the latter indicates the number of viral particles required to form one plaque in a plaque assay. Although highly variable, it is taken as a measure of the efficiency by which a virus infects cultured cells. Baranowski et al (1998) recorded 20 and $200 \mathrm{PFU} /$ cell for two different FMDV strains; Mueller et al. (2006) detected 157-272 PFU/particle for polio (also a single strand positive RNA virus) while Fields et al. (2007, p797) estimated that the range is 30-1000, thus giving a possible range of $6 \times 10^{2}-2 \times 10^{5}$ virions/cell. 
The exact response of cells to viral concentration is not well understood, but for high loads we estimate the minimum delay between infection and lysis is approximately three hours. When specialized baby hamster kidney (BHK) cells were infected with a British field strain of FMDV (O1BFS) and then monitored by immunofluorescence, FMDV protein could be detected in a discrete region on one side of the nucleus within 15-20 hours post infection. As the time post-infection increased, the viral proteins expanded to fill virtually all of the cytoplasm (Monaghan et al 2004). These BHK cell lines have been specifically cultured for the study of FMDV replication in vitro: they have been well characterized and are used extensively, and similar results are observed in primary bovine thyroid (BTY) cells infected with FMDV UKG 34/2001 (Zhang et al., unpublished data).

Within in-vitro culture, the cytopathic effect involves a number of distinct morphological stages, amongst which cells curling at the edges and subsequently becoming detached from the plate is considered a clear indicator of lytic death. BHK-21 cells infected with FMDV quickly "round up" in this way, with the majority of the cells floating into the medium in which they are cultured within 3 hours post infection (Monaghan et al., 2003). The exact time until cytopathic effect is likely to vary with strain virulence: Baranowski et al. (1998) observed complete cytopathic effects 4-6h with MARLS FMDV (a monoclonal antibody escape mutant) compared to 16-20h with C-58c1 FMDV. Pengyan et al. (2008) noted cytopathic effects 6 -8h post infection in cells initially infected with $5 \times 10^{3}$ the "50\% Tissue Culture Infective Dose" $\left(\mathrm{TCID}_{50}\right)$ per cell of FMDV, although this is not a particularly high dose and the experiment was only designed to observe cell changes at 10,12, 18, 24, 36 and $48 \mathrm{~h}$ post infection, while Escarmis et al. (1998) found complete cytopathic effects 16-20h after cells had been infected with a concentration of 5-10 $\mathrm{PFU} /$ cell. The rate of infected cell death for porcine epithelium was also estimated as $0.33 h^{-1}$ by Quan (2005).

Moore (1987) stated an ECM volume fraction of about $\omega^{*}=0.05$ in skin tissue, though details in how this value was measured are rather vague. This estimate for $\omega^{*}$ is most likely to have been estimated from 2-D skin sections, in which case $\omega^{*} \approx 2 \omega$; this approximation can be derived by assuming the rather ideal structure of a rectangular cell of width $d$ surrounded by ECM of width $l / 2$. Likewise, if the data was somehow obtained from 3-D skin tissue samples, then $\omega^{*} \approx 3 \omega$. Either way, the gap fraction is likely to be small with $0.01<\omega<0.05$; numerical results (see section 4) are not sensitive to changes in $\omega$ well beyond this range.

\begin{tabular}{llcl}
\hline & Parameter & \multicolumn{1}{c}{ Value } & Data source \\
\hline$\omega$ & Extracellular matrix volume fraction & $2.50 \times 10^{-2}$ & Moore (1987) \\
$\Gamma$ & Surface/interface cell turn-over rate & $2-6 \times 10^{-3} \mathrm{~h}^{-1}$ & Winning \& Townsend (2000) \\
$R$ & Proliferation rate of basal cells & $2.88 \times 10^{-2} \mathrm{cell} \mathrm{h}^{-1}$ & Potten et al. (2002a) \\
$\rho$ & Virus replication rate & $2.88 \times 10^{-1} \mathrm{cell} \mathrm{h}^{-1}$ & de Boer \& Bachrach (1961) \\
$\phi$ & Maximum cell death rate & $3.33 \times 10^{-1} \mathrm{~h}^{-1}$ & Monaghan et al. (2003) \\
$\kappa$ & Maximum viral concentration & $1.00 \times 10^{5}$ virions/cell & Garica-Arriaza et al. (2004) \\
\hline
\end{tabular}

Table 1: Independent model parameters.

To estimate the depth of non-keratinised epithelium, bovine tongue and soft palate tissue was taken from a previous cattle experiment (Zhang and Alexandersen, 2004) and fixed in formalin for 24 hours. Sections of epithelium were cut and stained with hematoxylin and eosin according to standard procedure and then inspected by microscope. Tissue thickness varied considerably, with the results given in Table 2 being an estimated average.

\begin{tabular}{lllcl}
\hline & parameter & region & value & data source \\
\hline \multirow{2}{*}{$C_{0}$} & \multirow{2}{*}{ Living cell layer depth } & tongue & 20 cells & \multirow{2}{*}{ bovine tissue sections (see text for details) } \\
& soft palate & 9 cells & \\
\hline
\end{tabular}

Table 2: Tissue specific model parameters.

The parameter $\theta=\delta / \mu$ represents the ratio of ECM associated virion washout rate and reinfection rate; in the absence of relevant data it is very difficult to estimate this parameter. The parameter $\mu$ combines virion traversal between cells and the attachment affinity to the cell membrane. The uptake 
of virus by cells is very rapid, with a penetration reaction half life of approximately 30 seconds recorded resulting in $90 \%$ infection complete within three minutes (Thorne, 1962). It is therefore appropriate to model extracellular viral dynamics based upon the diffusion time scales as discussed in section 2.2, noting the intercellular distance $l$ and inter-boundary distance $L$ discussed in Section 2.1. The latter process is likely to be relatively rapid in comparison to virion diffusion, so that the rate of virion traversal and cell binding is expected to be diffusion limited, which suggests $\mu \propto D / l^{2}$, where $D$ is the virion diffusion coefficient in ECM. Likewise, it is expected that the rate of virion washout through the epidermal surfaces is also diffusion limited, thereby $\delta \propto D / L^{2}$. Thus, we expect $\theta \propto l^{2} / L^{2}$ and using (3) we have

$$
\theta=\Theta \frac{\omega^{2}}{\left(C_{0}-1\right)^{2}},
$$

where $\Theta$ is a constant dependent on the skin structure and virus-cell attachment affinity that could potentially vary between the tongue and palate. We note for fixed $\Theta$ that $d \theta / d C_{0}<0$, which means that virion loss through the boundaries of the skin is reduced as the skin thickness increases. If $\Theta$ is the same in the tongue and palate then, using typical values for $C_{0}$ as given in Table $2, \theta$ in the tongue is approximately 0.18 that in the palate. It is probable that prior to the development of lesions, the corneal layer present in the tongue will act as a barrier to escape of the virion and loss from the epidermal layer will only occur through the basal layer. This means that the value of the constant $\theta$ in the tongue is likely to be somewhat smaller than that of the palate and hence $0.18 \theta_{\text {palate }}$ will be an upper-bound for $\theta_{\text {tongue }}$

The average proliferation rate $r$ for all cells in the model will be less than the proliferation rate $R$ of basal cells alone, since these make up only one layer. To relate the two we assume that a single cell in the virus-free system will divide at the same (constant) rate as a single basal cell. Explicitly, the time $t_{2}-t_{1}$ taken for the logistic equation

$$
C(t)=C_{0} \frac{C(0)}{C(0)+\left(C_{0}-C(0)\right) e^{-r t}}
$$

to reach $C\left(t_{2}\right)=2$ from $C\left(t_{1}\right)=1$ is $1 / R$. This implies that after lysis the epithelium in the tongue and palate would recover (from a single cell) to $41 \%$ and $20 \%$ of their original thickness after three days respectively, to $89 \%$ and $66 \%$ of their original thickness after one week respectively, and regain $95 \%$ of their original thickness (of 9 and 20 cells respectively) after 9 and 12 days respectively. This is comparable with empirical observations: lesions usually take 14 days or more to heal over after they initially form on the tongue in cattle (Anon, 1986), with sero-fibrinous exudation into the lesion observed around 3 days after they form (Anon, 1986). We take this exudation as the start of recover time point since it is also follows directly after the ulcer ceases to be bright red (Anon, 1986). Results are in line with the given transit time of epidermal cells from the basal region to the top of the viable epidermis for pigs and humans at 14 and 13 days respectively (Weinstein, cited by Bustad \& McClellan, 1965); unfortunately no cattle specific data is available.

\begin{tabular}{llllll}
\hline \multirow{2}{*}{ Parameter } & \multirow{2}{*}{ Formula } & \multicolumn{2}{c}{ Estimated value from Tables 1-2 } \\
& & Palate & Tongue & \\
\hline$r$ & cell proliferation rate & $R \ln \left[\left(C_{0}-1\right) /\left(C_{0} / 2-1\right)\right]$ & $2.39 \times 10^{-2}$ & $2.16 \times 10^{-2}$ & $\mathrm{~h}^{-1}$ \\
$K$ & Cell capacity & $C_{0}$ & 9 & 20 & cells \\
$\theta$ & Virus uptake to washout ratio & $\propto \omega^{2} /\left(C_{0}-1\right)^{2}$ & $9.77 \times 10^{-6} \Theta$ & $1.73 \times 10^{-6} \Theta$ & \\
\hline
\end{tabular}

Table 3: Dependent model parameters.

\section{Analytical results}

Equations (13) represent a negative feedback system, although it is difficult to formulate it as a predatorprey interaction since the interpretation of the predator response both to the prey-reproduction and prey-predation is unclear.

We first define a basin of attraction for solutions, confirming that results remain biologically relevant. 
Lemma 3.1 Define:

$$
\mathcal{B}=\left[0, C_{0}\right] \times[0, \kappa(\rho+\phi) / \rho] .
$$

Then $\forall(C(0), V(0)) \in \mathcal{B}$ solutions $(C(t), V(t))$ of (13) remain bounded by the region $\mathcal{B}$ for all $t \geq 0$.

Proof If $C=0$ or $V=0$ then $\dot{C}=0$ or $\dot{V}=0$ respectively, so that solutions are bounded below for all $C$ and all $V$. If $C=C_{0}$ then $\dot{C}=C\left[r / C_{0}\left(C_{0}-C\right)-\phi f(V)\right] \leq 0$ for all $V$ and so $C$ is bounded above. Finally, $C \leq C_{0}$ implies, since $C<E_{0}$, that $\dot{V}<V\left[\rho / \kappa\left(V_{\infty}-V\right)+C r / C_{0}+\phi f(V)\right]$ where $V_{\infty}$ is defined in Lemma 3.3. For $V=\kappa(\rho+\phi) / \rho$ we therefore have $\dot{V}=V\left[\phi(f(V)-1)+r / C_{0}\left(C-C_{0}\right)\right] \leq 0$ for $C \leq C_{0}$ and $f(V) \leq 1$, so that $V$ is also bounded above.

\subsection{Transient dynamics}

We expect the initial infection to consist of a relatively small virus load, so that $V(0) \ll \kappa$, seeded into the cell population which is at equilibrium i.e. $C(0)=C_{0}$. Of interest is the initial replication of virus and what factors might induce rapid expansion resulting in severe lysis prior to any inhibition from the immune response.

Lemma 3.2 For $V(0) \ll \kappa$ the initial virus concentration in a cell population $C_{0}$ is approximated by:

$$
V(t) \approx V(0) e^{\rho t}, \quad \text { for } t \ll \frac{1}{\rho} \ln \frac{\kappa}{V(0)} .
$$

PRoof Applying regular perturbation techniques on $V$ and $C$ for small $\varepsilon=V(0) / \kappa$, we substitute $V \sim \varepsilon V_{[1]}(t)+\varepsilon^{2} V_{[2]}(t)$ and $C \sim C_{0}+\varepsilon C_{[1]}(t)$ into (13), then expand and match terms in powers of $\varepsilon$. Solving in sequence the resulting ODEs, the following expansions are generated

$$
\begin{aligned}
C & \sim C_{0}-\varepsilon C_{[1]}^{*} e^{\rho t}\left(1-e^{-(r+\rho) t}\right), \\
V & \sim \varepsilon \kappa e^{\rho t}+\varepsilon^{2} V_{[2]}(t),
\end{aligned}
$$

where $C_{[1]}^{*}=\kappa C_{0} f^{\prime}(0) \phi /(\rho+r)$ is a constant and $V_{[2]}(t)$ is a rather long function (that has been omitted for brevity) with the key property that $V_{[2]}(t) \sim V_{[2]}^{*} e^{2 \rho t}$ as $t \rightarrow \infty$ for some constant $V_{[2]}^{*}$. These approximations breakdown at approximately the point in time in which the second term in each expansion is equal to the first term; in both cases, at leading order, this occurs in large time when $t \sim \ln (1 / \varepsilon) / \rho$ as $\varepsilon \rightarrow 0$. The statements in the lemma result from substituting $\varepsilon=V(0) / \kappa$.

This lemma indicates that model will always predict the development of the disease in an animal regardless of the size of the initial inoculation and that the symptoms will be observable in a timescale of

$$
t=\frac{1}{\rho} \ln \left[\kappa\left(1+\theta\left(E_{0} / C_{0}-1\right)\right) / v_{0}\right],
$$

after the initial infection, where $v_{0}$ is the initial virus concentration in the ECM for the full model (see section 2.4.1). Thus, a reduction in the initial dose and/or viral growth rate will mean that the disease will take longer to cause observable damage to an infected animal, as would be expected. It must be remembered, however, that the model only describes the system prior to the immune response so that results are only valid for a time period of a few days: if the timescale for infection above is longer than this then alternative disease dynamics may be expected in practice.

\section{$3.2 \quad$ Asymptotic dynamics}

Henceforth we assume that $(C(0), V(0)) \in \mathcal{B}$ since in practice $C(0)=C_{0}$ and $V(0) \ll \kappa$. We next consider the possible equilibria of the solution (their existence and stability), since we are particularly interested in conditions leading to steady persistence of virus. We start by presenting a lemma that summarises existence and stability of the trivial steady-states and move on to discuss the existence and stability of coexistent states in lemma 3.4 and beyond. 
Lemma 3.3 This lemma is in four parts.

(i) The system (13) possesses a trivial equilibrium $(0,0)$, the non-negative equilibrium $\left(C_{0}, 0\right)$ and, iff $\rho>r$, the non-negative equilibrium $\left(0, V_{\infty}\right)$ where $V_{\infty}=\kappa(\rho-r) / \rho$. All other equilibria are strictly positive with the existence and multiplicity of such solutions dependent on the lytic response function $\phi f(V)$.

(ii) The trivial equilibrium $(0,0)$ of (13) always exists and is always unstable.

(iii) The virus-free equilibrium $\left(C_{0}, 0\right)$ of (13) always exists but is always linearly asymptotically unstable.

(iv) The cell extinction equilibrium $\left(0, V_{\infty}\right)$ of (13) exists for $\rho>r$ and is linearly asymptotically stable iff, in addition to this, $f\left(V_{\infty}\right)>r / \phi$.

PROOF (i) By direct analysis of the null-clines.

(ii) The eigenvalues of the system linearised about $(0,0)$ are given by $\rho-r$ and $r>0$.

(iii) The eigenvalues of the linearised system are given by $-r$ and $\rho>0$.

(iv) Again, the first condition ensures that $V_{\infty}$ is positive while the second follows from the eigenvalues of the linearised system being given by $r-\rho$ and $r-\phi f\left(V_{\infty}\right)$.

The $(0,0)$ equilibrium represents the extinction of both virus and cells including the extinction of cells in the absence of virus: since there should be no reason for virus-free tissue not to endure, it is appropriate that this not be attractive in any realistic parameter space, Lemma 3.3(ii). The second equilibrium $\left(C_{0}, 0\right)$ in Lemma 3.3(i) represents the clearance of virus. Since this is thought to only be achieved by the immune response (which has not been included in the model), we would again expect this not to be attractive in any biologically reasonable parameter space, Lemma 3.3(iii). Note that both these states (their existence and linear stability) are independent of the lytic response $\phi f(V)$, both its strength and form.

This final state $\left(0, V_{\infty}\right)$ discussed in Lemma 3.3(i) may seem counter-intuitive since virus cannot exist in the absence of cells, but it should be remembered that $V$ represents virus concentration, not virus load. Thus $V_{\infty}$ can be seen as the terminal virus concentration as the last cell is killed, were the system to continue indefinitely without any immune response. We consider this equilibrium as representative of the scenario of escalating lysis.

We now restrict ourselves to qualitatively realistic forms for $f(V)$, as explained in section 2.2 , and present a lemma for the existence of a coexistent state in which cells and virus are both present.

Lemma 3.4 The system (13) satisfying (5) has a unique positive equilibrium $\left(C^{*}, V^{*}\right) \in \mathcal{B}$ if (i) $r>\phi$ or (ii) $f\left(V_{\infty}\right)<r / \phi$; furthermore in case (i) $V^{*} \in(0, \kappa)$ and in case (ii) $\max \left(0, V_{\infty}\right)<V^{*}<\min \left(V_{c}, \kappa\right)$ where $V_{c}$ is defined as $V_{c}=\min \{V: f(V)=r / \phi\}$.

PROoF Intersection of the null-clines of (13) indicate that any equilibrium $\left(C^{*}, V^{*}\right)$ must satisfy

$$
C^{*}=C\left(V^{*}\right)=C_{0}\left(1-\frac{\phi f\left(V^{*}\right)}{r}\right),
$$

and $V^{*}$ is the solution of $P\left(V^{*}\right)=0$ where

$$
P(V)=(1-V / \kappa)-\frac{r \theta}{\rho} \frac{\left(1-C(V) / C_{0}\right)\left(E_{0}-C(V)\right)}{C(V)(1-\theta)+\theta E_{0}},
$$

using (13) and $\phi f(V)=r\left(1-C(V) / C_{0}\right)$ from the above formula for $C(V)$. Since $f^{\prime}(V) \geq 0$ then $C^{\prime}(V)=-\phi f^{\prime}(V) / r \leq 0$. We note that $P(0)=1>0$ and that the derivative of $P(V)$ is

$$
\begin{aligned}
P^{\prime}(V)=-\frac{V}{\kappa}+C^{\prime}(V) & \frac{r \theta}{\rho\left(C(V)(1-\theta)+\theta E_{0}\right)^{2}} \\
& \times\left\{\left[\left(E_{0}-C(V)\right) / C_{0}+\left(1-C(V) / C_{0}\right)\right]\left(C(V)(1-\theta)+\theta E_{0}\right)\right. \\
& \left.\quad+(1-\theta)\left(1-C(V) / C_{0}\right)\left(E_{0}-C(V)\right)\right\} .
\end{aligned}
$$

We note further that if $C(V)>0$ then $P^{\prime}(V)<0$, as $C^{\prime}(V)<0$ and $C(V) \leq C_{0}<E_{0}$. The aim in the remainder of the proof is to find $V=V_{m}$ such that $C\left(V_{m}\right) \geq 0$ and $P\left(V_{m}\right)<0$, so we can deduce by continuity that there exists $V^{*} \in\left(0, V_{m}\right)$ such that $P\left(V^{*}\right)=0$ and $C^{*}=C\left(V^{*}\right)>0$. In case (i) we choose $V_{m}=\kappa$ and in case (ii) $V_{m}=V_{c}$, where $f\left(V_{c}\right)=r / \phi$, which will be further refined to $V_{m}=\kappa$ when $\kappa<V_{c}$. 
(i) If $r>\phi$ then $C(V) \in\left[C_{0}(1-\phi / r), C_{0}\right]$ for all $V>0$, thereby $C(V)$ is strictly positive. Evaluating $P(\kappa)$ we obtain

$$
P(\kappa)=-\frac{r \theta}{\rho} \frac{\left(1-C(\kappa) / C_{0}\right)\left(E_{0}-C(\kappa)\right)}{C(\kappa)(1-\theta)+\theta E_{0}}<0,
$$

since $0<C(\kappa) \leq C_{0}<E_{0}$, hence there exists $V^{*} \in(0, \kappa)$ satisfying $P\left(V^{*}\right)=0$ by continuity. We note also that $C^{*}=C_{0}\left(1-\phi f\left(V^{*}\right) / r\right)>0$ is trivially satisfied.

(ii) For $r<\phi$, we note that $f\left(V_{\infty}\right)<r / \phi$ implies $V_{\infty}<V_{c}$ since $f^{\prime}(V) \geq 0$ and hence for $V \in\left(0, V_{c}\right)$ we have $C(V) \in\left(0, C_{0}\right]$; it therefore follows that $P^{\prime}(V)<0$ in this range. Evaluating $P\left(V_{c}\right)$ leads to

$$
P\left(V_{c}\right)=\left(1-V_{c} / \kappa\right)-\frac{r}{\rho}=\frac{1}{\kappa}\left(V_{\infty}-V_{c}\right)<0,
$$

since $V_{\infty}<V_{c}$. Thus by continuity of $P(V)$, there exists $V^{*} \in\left(0, V_{c}\right)$ satisfying $P\left(V^{*}\right)=0$ and $C\left(V^{*}\right)>0$. To refine this bound on $V^{*}$, we note first that if $V_{\infty}<0$ then $V^{*}>0>V_{\infty}$ is trivially satisfied and if $V_{\infty}>0$ then we have, after a little manipulation,

$$
P\left(V_{\infty}\right)=\frac{r C\left(V_{\infty}\right)\left(C_{0}+\theta\left(E_{0}-C\left(V_{\infty}\right)\right)\right)}{\rho C_{0}\left(C\left(V_{\infty}\right)(1-\theta)+\theta E_{0}\right)}>0,
$$

since $C\left(V_{\infty}\right)>0$ and $C(V) \leq C_{0}<E_{0}$; hence $V_{\infty}<V^{*}$. To prove the upper bound of $V^{*}$, if $\kappa<V_{c}$, then $C(\kappa)>0$ and from the same method of proof for case (i) we deduce that $P(\kappa)<0$. Thus $\max \left(0, V_{\infty}\right)<V^{*}<\min \left(V_{c}, \kappa\right)$ follows.

We consider this equilibrium to represent persistence of virus within cells, since both populations are able to coexist and survive i.e. the scenario envisaged to occur in the palate; this is explored more in Section 5. The upper bound $V^{*}<\kappa$ suggests that if $V(0)<\kappa$ (i.e. a suitably small initial infection) the virus load never reaches its carrying capacity within the cell, which is perhaps not obvious from (13). The reason is that cells die due to the virus before the load reaches such levels. Furthermore, the last part of case (ii) of Lemma 3.4 is interesting in that where an extinction state is possible, i.e. $V_{\infty}>0$, then the population density of the virus in the coexistence state will be greater than that of the extinction state. We note if $V_{\infty}<0$, then there always exist positive equilibrium $\left(C^{*}, V^{*}\right) \in \mathcal{B}$. In the forthcoming discussion it is useful to define the constant $\sigma$ as follows

$$
\sigma= \begin{cases}r / \phi f\left(V_{\infty}\right) & \rho>r \\ +\infty & \rho<r,\end{cases}
$$

where we have effectively assigned $f\left(V_{\infty}\right)=0$ for $V_{\infty}<0$ corresponding to when $\rho<r$. It follows from Lemma 3.4, that existence of the positive equilibrium $\left(C^{*}, V^{*}\right)$ requires $\sigma>1$.

The conditions for the existence of a persistence state and those for the local attractiveness of the lytic explosion state are mutually exclusive. We summarise this in the following theorem:

Theorem 3.5 For $(C(0), V(0)) \in \mathcal{B}$, the dynamics of the system (13) with (5) as $t \rightarrow \infty$ depends on $\sigma$ in the following way

$$
\begin{aligned}
& \text { If } \sigma<1 \text { then }(C, V) \rightarrow\left(0, V_{\infty}\right) \text {. } \\
& \text { If } \sigma>1 \text { then }(C, V) \rightarrow\left(C^{*}, V^{*}\right) \text { or a limit cycle. }
\end{aligned}
$$

PROOF In all cases, to show that the equilibrium is a spiral, centre or node we consider the system linearised about $\left(C^{*}, V^{*}\right)$ in matrix form. The product of the eigenvalues of the linear system is given by the determinant of this matrix $M$ :

$$
\operatorname{det}(M)=\frac{C^{*} V^{*} r \rho}{C_{0} \kappa}+\frac{C^{*} V^{*} \phi \theta\left(\phi f\left(V^{*}\right) C_{0} E_{0}+r\left(E_{0}-C^{*}\right)\left(C^{*}(1-\theta)+\theta E_{0}\right)\right) f^{\prime}\left(V^{*}\right)}{C_{0}\left(C^{*}(1-\theta)+\theta E_{0}\right)^{2}} .
$$

This is always positive since $0<C^{*}<E_{0}$, i.e. real roots of opposite sign are not possible.

For $\rho<r(\sigma=+\infty)$, the steady-state $\left(C^{*}, V^{*}\right)$ is the only equilibrium inside $\mathcal{B}$ with no stable equilibria on the boundary of $\mathcal{B}$ from Lemma 3.4 and noting that $V_{\infty}<0$ in this case. Since $\operatorname{det}(M)>0$, so that $\left(C^{*}, V^{*}\right)$ is not a saddle-point, the result follows by the Poincaré-Bendixon theorem.

For $\rho>r$ and $r / \phi f\left(V_{\infty}\right)<1(\sigma<1)$ there exists no equilibria inside $\mathcal{B}$ and $\left(0, V_{\infty}\right)$ is the only stable equilibrium on the boundary of $\mathcal{B}$; convergence to $\left(0, V_{\infty}\right)$ follows from the Poincaré-Bendixon theorem. For $\rho>r$ and $r / \phi f\left(V_{\infty}\right)>1(\sigma>1)$, there are no stable equilibria on $\mathcal{B}$ and since $\left(C^{*}, V^{*}\right)$ is the only equilibria in $\mathcal{B}$ the result follows again by the Poincaré-Bendixon theorem. 


\begin{tabular}{ccc}
\hline Equilibrium solution & Condition for existence & Condition for linear stability \\
\hline$(0,0)$ & always & never \\
$\left(C_{0}, 0\right)$ & always & never \\
$\left(0, V_{\infty}\right)$ & $\rho>r$ & $\sigma<1$ \\
$\left(C^{*}, V^{*}\right)$ & $\sigma>1$ & $\tau<0$ \\
\hline
\end{tabular}

Table 4: Analysis summary of Section 3.2, where $\sigma$ and $\tau$ are given by (19) and (20), respectively. Here "existence" refers to existence of relevant solution in $\mathcal{B}$

The only loose end following Theorem 3.5 is that given there exists a coexistent state in $\mathcal{B}$, do we expect $(C, V) \rightarrow\left(C^{*}, V^{*}\right)$ or a limit cycle solution. Limit cycle solutions represent periodic changes in cell numbers and virus load, so there will be cyclical phases of recovery and degeneration of skin tissue. In reality, the timescales are such that other events not described by the current model, such as immune response, will come into play before the periodic behaviour manifest itself. Nevertheless, for completeness, we resolve the issue of whether or not limit cycles will result in Theorem 3.6.

Theorem 3.6 If $\rho<r$ or $\rho>r$ and $\sigma>1$, so that there exists a steady-state $\left(C^{*}, V^{*}\right) \in \mathcal{B}$ of $(13)$, then:

if $\tau<0$ all solutions in $\mathcal{B}$ converge to the unique strictly positive equilibrium $\left(C^{*}, V^{*}\right)$;

if $\tau>0$ all solutions in $\mathcal{B}$ converge to a limit cycle;

where

$$
\tau=V^{*} \frac{f^{\prime}\left(V^{*}\right)}{f\left(V^{*}\right)}\left(\left(\frac{V^{*}}{\kappa}-1\right)+\frac{\phi f\left(V^{*}\right)}{\rho}\right)-\left(\frac{r}{\rho} \frac{C^{*}}{C_{0}}+\frac{V^{*}}{\kappa}\right) .
$$

PROOF This follows directly from $\tau=\operatorname{trace}(M) / \rho$, where $M$ is the matrix introduced in the proof of Theorem 3.5.

Table 4 lists all the steady-states and the conditions for their existence and stability; thus summarising the Theorems and Lemmas of this section. It is therefore straightforward using the above analysis to compute the large time outcome given a parameter set. However, to make further analytical progress, we will investigate the steady-state solutions in the biologically relevant case $r \ll \rho$.

\subsection{The limit $r / \rho \rightarrow 0$}

So far in Section we have made no restrictions on the parameters. There is clear experimental evidence (by orders of magnitude - see section 2.3) that the rate of virus replication exceeds that of cells. This means that we expect $r / \rho \ll 1$ (see Tables 1 - 3). Defining $\varepsilon=r / \rho$, we seek steady-state solutions of the coexistence state of the form

$$
C^{*} \sim C_{[0]}^{*}+\varepsilon C_{[1]}^{*}, \quad V^{*} \sim V_{[0]}^{*}+\varepsilon V_{[1]}^{*} .
$$

as $\varepsilon \rightarrow 0$. On substitution into (17) and (18), we make series expansions in powers of $\varepsilon$, where we find that

$$
C_{[0]}^{*}=C_{0}\left(1-\frac{\phi f(\kappa)}{r}\right)
$$

and

$$
\begin{aligned}
C^{*} & \sim C_{[0]}^{*}-\varepsilon \frac{C_{0} \phi \kappa f^{\prime}(\kappa)}{r}\left(\frac{\theta\left(1-C_{[0]}^{*} / C_{0}\right)\left(E_{0}-C_{[0]}^{*}\right)}{C_{[0]}^{*}(1-\theta)+\theta E_{0}}\right) . \\
V^{*} & \sim \kappa-\varepsilon \kappa \frac{\theta\left(1-C_{[0]}^{*} / C_{0}\right)\left(E_{0}-C_{[0]}^{*}\right)}{C_{[0]}^{*}(1-\theta)+\theta E_{0}} .
\end{aligned}
$$


We note that these expansions are only valid if $C_{[0]}^{*}>0$ requiring $\phi f(\kappa) / r<1$, which corresponds to the $\sigma>1$ case in Theorem 3.5. We note that in agreement with the proof of Lemma 3.4, that $-V_{[1]}^{*}<\kappa$ hence $V_{\infty}<V^{*}$, where $V_{[1]}^{*}$ is the $O(\varepsilon)$ term in (23).

As expected, if the virus replicates rapidly in comparison to the cells, its population density grows near to its carrying capacity $\kappa$. For $\sigma>1$ we obtain

$$
\tau \sim \frac{\kappa \phi f^{\prime}(\kappa)}{\rho}-1
$$

to leading order as $\varepsilon \rightarrow 0$, resulting in a somewhat simpler expression for $\tau$ to determine the stability of $\left(C^{*}, V^{*}\right)$ in the $\varepsilon \ll 1$ case. The upshot is that if $f(V)$ is "sufficiently steep" in the vicinity $V=\kappa$, such that $f^{\prime}(\kappa)>\rho / \phi \kappa$, limit cycle solutions will result. Biologically, the statement "sufficiently steep" means that the extent of skin cell death is highly sensitive to viral load around $V \approx \kappa$.

Perhaps the most important result from this analysis is that the predicted extent of skin damage is a linear function of the original thickness $C_{0}$ of the skin to leading order, as given by equation (21). This is illustrated in the numerical results presented in Section 4. In effect, the model predicts that the virus will damage a fixed fraction of the skin (specifically $1-\phi f(\kappa) / r$ ), independent of location, however, the consequence of such damage will vary depending on mechanical stress that the skin is experiencing.

It is worth noting that in the limit $\varepsilon \rightarrow 0$, singular perturbation analysis can be applied to equations (13) to reveal the evolutionary behaviour of $(C, V)$ towards the steady-state expansions (22)-(23). We will omit the details and instead summarise the results. Following the introduction of the virus, the virus infiltrates cells and their density grows rapidly over a timescale of $O(\ln (\kappa / V(0)) / \rho)$ hours to reach $V \sim \kappa$, in the mean time skin cells are relatively unaffected. In longer time, the balance $V \sim \kappa$ is sustained and the cell density will vanish exponentially if $\sigma<1$ or tend to (22) for $\sigma>1$.

\section{Numerical results}

Simulations of the system (13) for the parameter values given in Table 1 are dominated by the high lytic rate $\phi$ and the relative low cell proliferation rate $r$ compared to the virus replication rate $\rho$ : Figure 3 shows that the cases $C_{0}=20$ (as estimated for the tongue) and $C_{0}=9$ (as estimated for the palate) produce near identical results. The exact shape of the response in $C(t)$ is dependent on the functional form of $f(V)$ as we would expect (with sharper transitions in the lytic response mirrored in cell populations), although reasonable alternatives do not appear to induce qualitative changes in dynamics. Results presented here assume that half the maximum lytic response rate is achieved when viral concentration is at half its observed maximum - so that $k=\kappa / 2$ in (6) - the same as would occur for a linear response. For an asymptotic function of the form (6) we note that the proportion of the maximum lytic response rate that can actually be achieved at the maximum sustainable virus concentration $\kappa$ satisfies $f(\kappa)=1 /\left(1+2^{-n}\right)<$ 1. We use $n=2$, which implies $f(\kappa)=80 \%$, in what follows but results are not qualitatively sensitive to this with the exception of extremely steep $f(V)$ (as discussed in section 3.3) .

The model captures well the behaviour observed in the tongue, as shown in Figure 1. These photos show a rapid transition from unruptured vesicles to large lesions within one day: note that these images are timed from the day when any form of epithelial damage is first observed, as opposed to the time that tissue is first infected (the abscissa in the figures that follow). Model simulations predict a rapid decay in cell numbers after an initial delay (determined by the initial virus concentration) over the same time-scale with local extinction of cells (through lysis) and hence intracellular virus. In practice extracellular and washed out virus will be free to infect cell populations elsewhere, but modification of the parameter $\theta$ does not affect the system for all but infeasibly large changes in order of magnitude (in what follows we take $\Theta=1$ in equation (15) for both tongue and palate). A simulation of the system with predicted parameter values is given in Figure 3(a).

Bifurcation from extinction to persistence (Theorem 3.5) can be shown to occur, but only if: $C_{0}$ is significantly smaller; $\phi$ is lower; $\rho$ is lower; or $R$ is much higher - or some combination of the above compared to the estimated values. In all cases a large reduction in the rate of lysis $(\phi)$ is required for the surviving cell population in the persistent case to be significantly different from zero (i.e. the extinction limit). It is reasonable to assume, however, that the maximum rate of lysis will be lower in-vivo than in-vitro (where the relevant experimental data given in Table 1 was derived), since in a live animal there may be innate resistance and extra cell structure inhibiting virus. Figure 3(b) shows that divergent behaviour can occur driven purely by the known differences in tissue thickness between the tongue and 

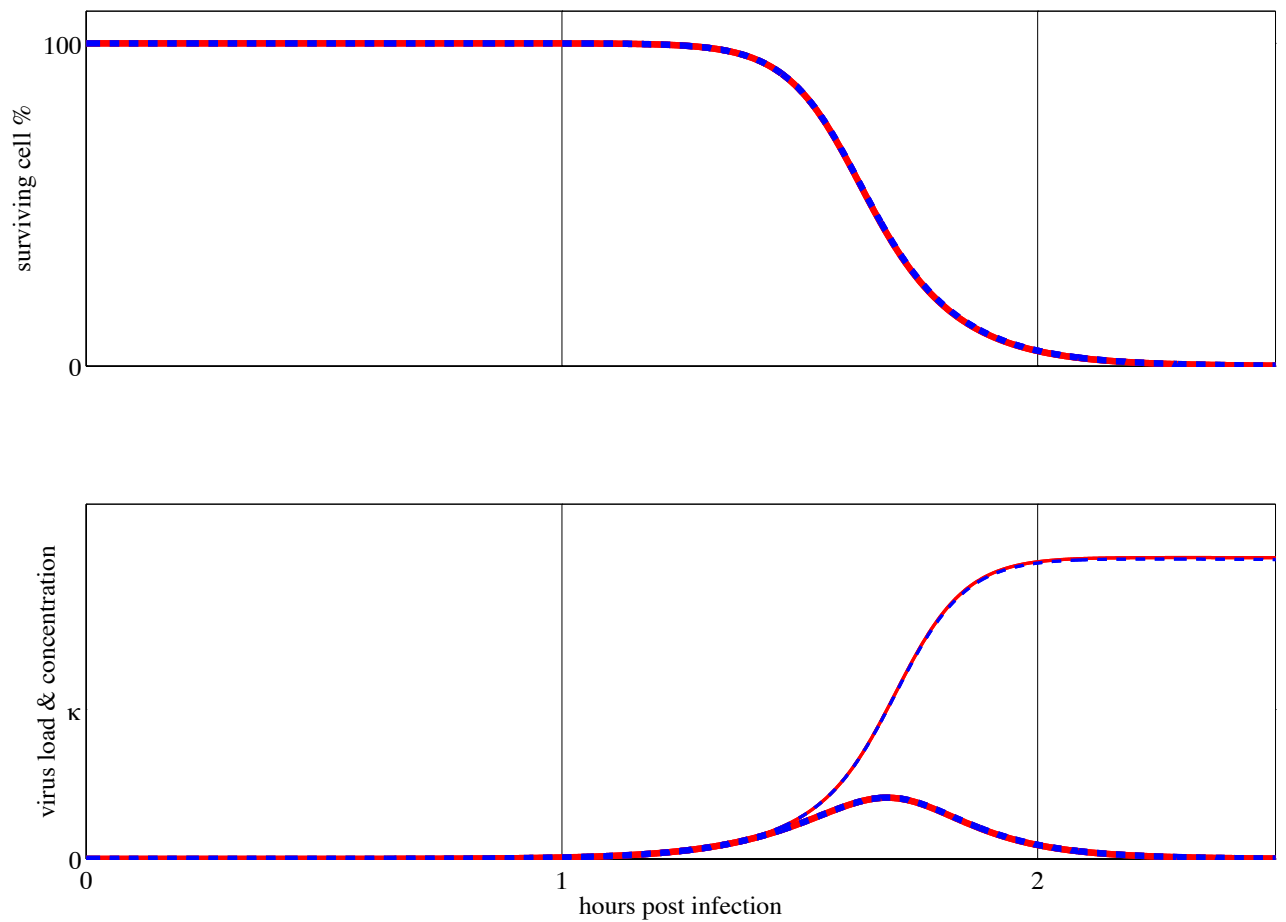

(a)

Figure 3: Predicted cell population $C$ (top), virus concentration $V$ (bottom: thin line) and the subsequent virus load $C V$ (bottom: thick line). (a) $C_{0}=9$ (dashed line) and $C_{0}=20$ (solid line), with all other parameters are equal and as given in Table 1; initial conditions $C(0)=C_{0}, V(0)=1$; results are virtually indistinguishable. (b) $C_{0}=3$ (dashed) and $C_{0}=20$ (solid) with other parameters as in (a) except for $\phi \rightarrow \phi / 5, R \rightarrow 2 R$; initial conditions $C(0)=C_{0}, V(0)=\kappa / 2$ : the thinner skin layer converges towards persistent viral coexistence while the thicker layer tends to extinction, but over a longer timescale. (c) $C_{0}=3$ (dashed) and $C_{0}=20$ (solid) with parameters as in (a) except for $\phi \rightarrow \phi / 5$ (everywhere) and $R \rightarrow 5 R$ in the palate only; initial conditions $C(0)=C_{0}, V(0)=\kappa / 2$ : the thinner skin layer converges towards persistent viral coexistence while the thicker layer tends to extinction over the empirically observed timescale.

palate, although in the absence of any other differences between the regions the full extent of this only becomes apparent beyond the timescale of the model (limited to day two or three). Divergent behaviour can be induced over this timescale through differences in other intrinsic properties - Figure 3(c), for example, shows steady viral persistence in the palate and near extinction in the tongue achieved within two days as a result of differences in the basal cell proliferation rate between these regions.

\section{Conclusions}

Understanding the dynamics of FMDV is essential for the control of FMD, which has a global impact on agriculture and thus livelihoods. One aspect which is currently not well understood is the divergent behaviour observed within bovine oral epithelium, where very different levels of lysis in the short term (and potential persistence of virus in the long term) are observed in the soft palate compared to other areas such as the tongue.

In this paper we have shown that the difference in the dimensions of these epithelial regions alone is theoretically sufficient to result in a bifurcation from lytic-driven local extinction of cells to the persistence of virus within a sustained host cell population. 

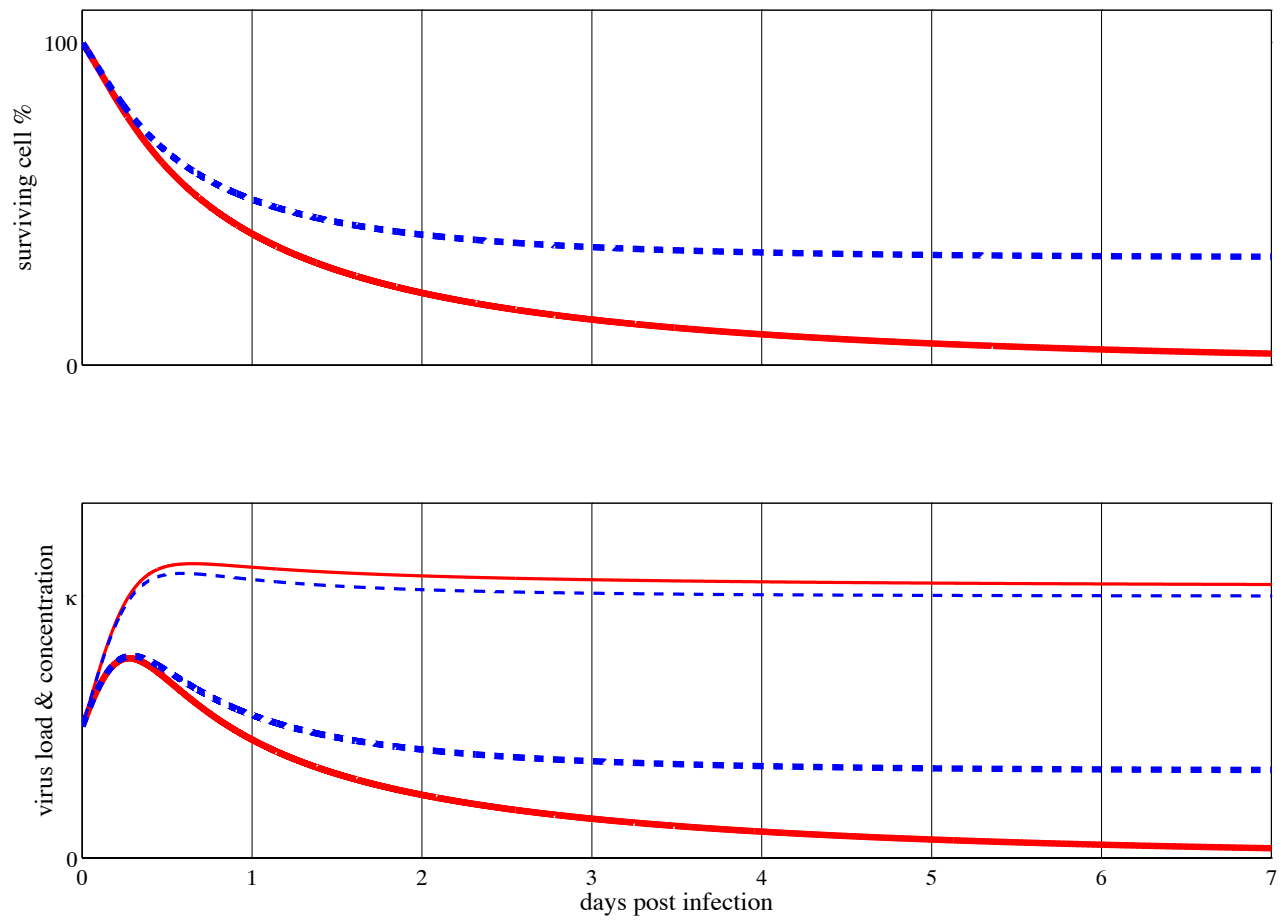

(b)
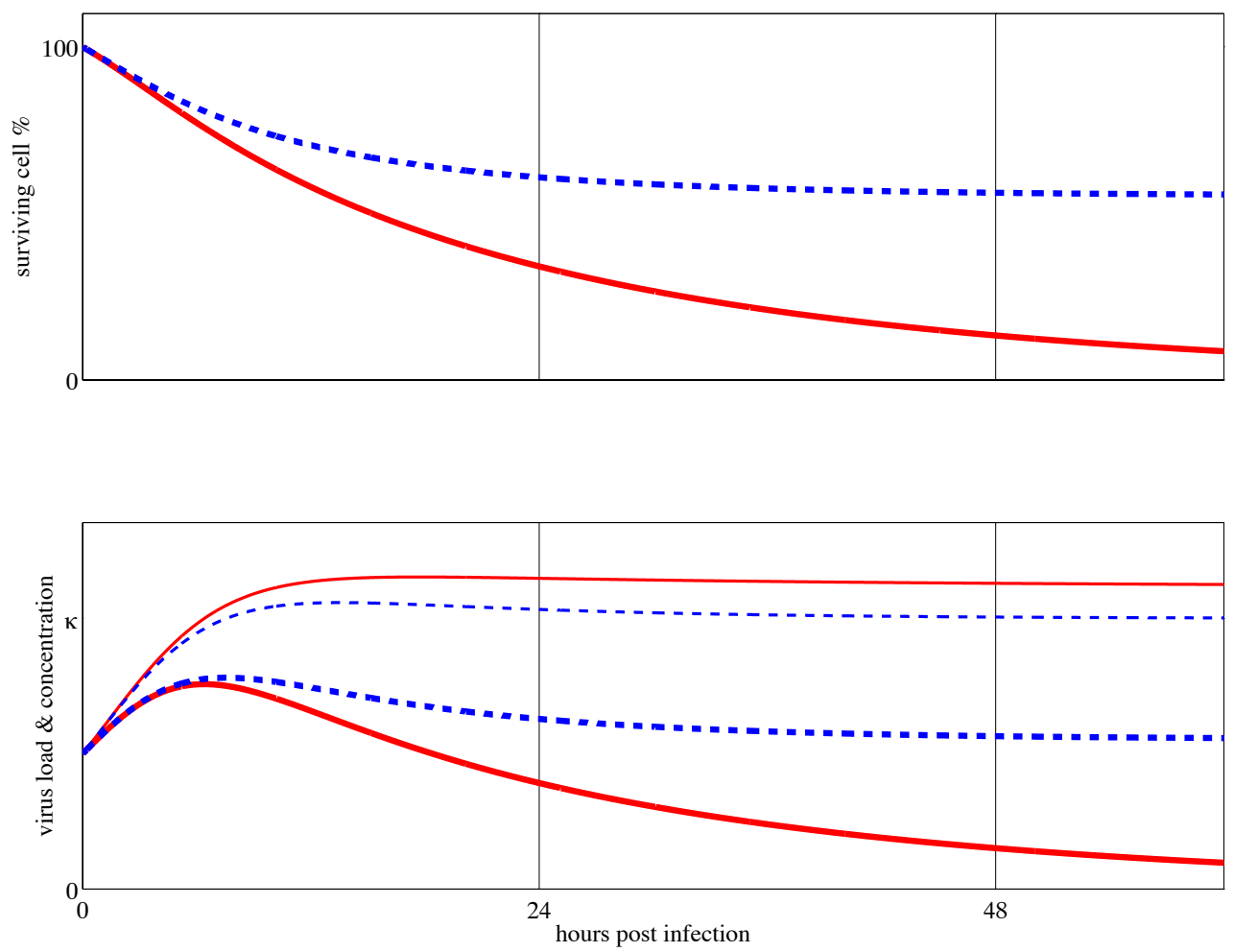

(c) 


\section{Determinants of lysis}

The gross histological differences between the epidermal tissues of the tongue and the soft palate are skin thickness and the presence of a keratinised layer: these aspects are dictated in our model by parameters $C_{0}$ (governing the number of live cell layers) and $\theta$ (the wash-out to uptake rate of virus ratio) respectively. Analysis in Section 3.2 (summarised in Table 4) indicates that the former is capable of driving bifurcation from extinction to persistence, but not for predicted parameter values, while the later appears to induce only negligible qualitative or quantitative changes.

Current best estimates for biological parameters, which assume that all intrinsic properties of cells and virions are the same in both the tongue and palate, indicate that $\sigma<1$ in both regions, resulting in short-term solutions tending to extinction i.e. lesions in cell tissue. With minor adjustments to the parameters $R$ and $\phi$, however, we can qualitatively reproduce the observed damage and, in particular, the contrast between responses in thin and thick tissue; such adjustments are probably not unreasonable given that most parameter estimates are derived in-vitro while the phenomenon under investigation occurs in-vivo. Furthermore, if the in-vivo cell death rate is significantly lower than that observed in-vitro, then co-existence in both the tongue and palate (as opposed to eventual extinction in both) would be predicted. In this case it may be important to also consider differences in the stresses and strains exerted on tissue in different regions, with the potential for mechanical damage in the tongue resulting from small lesions.

\section{Viral persistence}

The divergent response of the palate and tongue could be explained by a number of parameters within this system if their values were shown to be different between these regions: these are summarised in Table 5. The exact magnitude of changes required (compared to the experimental estimates given in Table 1) can be derived explicitly from (19).

\begin{tabular}{rlccc}
\hline & Parameter & $\begin{array}{c}\text { Transient: } \\
\text { high initial } \\
\text { virus concentration }\end{array}$ & $\begin{array}{c}\text { Asymptotic: } \\
\text { eventual } \\
\text { persistence }\end{array}$ & $\begin{array}{c}\text { Experimentally } \\
\text { observed } \\
\text { differences }\end{array}$ \\
\hline$C_{0}$ & living cell layer depth & & lower & lower in palate \\
$R$ & basal cell proliferation rate & higher & lower & \\
$\rho$ & virus replication rate & lower & \\
$\phi$ & maximum cell death rate & & lower & \\
$\kappa$ & maximum virus concentration & & & \\
\hline
\end{tabular}

Table 5: Comparison of experimental data and available physical results with analytical predictors for divergent behaviour; ${ }^{\dagger}$ See Table 2 for details.

Results indicate that persistence of virus within a surviving cell population could be achieved within the palate if it could be shown either that viral replication were significantly lower, or the proliferation rate of basal cells significantly higher - or, rather obviously, the rate of lysis amongst equivalently infected cells were lower - than in other tissue. Surprisingly, neither virus uptake or wash-out appear capable of inducing qualitative differences in the asymptotic dynamics. Although some of these differences have been hypothesised, at present there appears little experimental evidence to validate these and, furthermore, no proposed mechanisms to explain them. The modelling work presented here, however, supports the call for these properties to be explored further: consequently a number of simple in-vitro experiments to compare proliferation of, virus replication within and lysis of, cells cultured from different epithelial regions are now planned.

It is also important to note that the model describes events prior to the immune response, and thus the time when the virus is least inhibited. Large differences in the short-term behaviour between regions, resulting in distinct initial conditions for the body's response to infection, may therefore be sufficient to result in divergent long-term behaviour in these regions, even if their predicted asymptotic outcomes in the initial model are the same (since these are never realised on a realistic timescale). In addition to the physiological differences described above, such results are also possible in this model if the initial virus load is sufficiently different in each region i.e. differences in $V$ at the start of the modelled timeframe result in differences in $C$ at the end. 


\section{Tissue structure}

In the simple model presented here we expect all tissue to exhibit a rapid explosion in virus resulting in a continuous decay in cell numbers (at least prior to the immune response, at which point the model ceases to be valid). Since in practice this is only observed in the tongue, however, we hypothesise that either there are differences in the intrinsic cell and/or virion properties in the palate which have not yet been recognised, or that other histological properties of the tissue are responsible. Extension of the model to incorporate an explicit spatial structure is work in progress, and will include the effect of the cornified structure in non-pharyngeal epithelium and the potential role of lymphocytes. Incorporation of age dependent differentiated cell structure will also allow for the modelling of cell-specific viral responses (such as cytokine responses) which can be based upon proven differences in cell layers, as opposed to proposed differences in tissue regions.

\section{Acknowledgements}

The authors would like to thank all those participants of the 7th UK Mathematics in Medicine Study Group (Southampton, UK; September 2007) who contributed at the inception of this work. This work was funded by the Biotechnology and Biological Sciences Research Council [IAH1444].

\section{References}

ALEXANDERSEN, S., ZHANG, Z., DONALDSON, A. I. \& GARLAND, A. J. M. (2003) The Pathogenesis and Diagnosis of Foot-and-Mouth Disease. Journal of Comparative Pathology, 129 1-36.

ANON (1986). Foot-and-mouth disease: Ageing of lesions. Reference book 400, Her Majesty's Stationary Office, London.

BARNETT, P. V. \& COX, S. J. (1999) The Role of Small Ruminants in the Epidemiology and Transmission of Foot-and-Mouth Disease. The Veterinary Journal, 158 6-13.

BROWN, J. K., MCALEESE, S. M., THORNTON, E. M., PATE, J. A., SCHOCK, A., MACRAE, A. I., SCOTT, P. R., MILlER, H. R. P. \& COLliE, D. D. S. (2006) Integrin $\alpha v \beta 6$, a Putative Receptor for Foot-and-Mouth Disease Virus, Is Constitutively Expressed in Ruminant Airways. Journal of Histochemistry and Cytochemistry, $\mathbf{5 4} 807$.

BUSTAD, L.K. \& MCCLLELLAN, R.O. (1965) Use of pigs in biomedical research. Nature 208, 531-535.

DAWE, P. S., FLANAGAN, F. O., MADEKUROZWA, R. L., SORENSEN, K. J., ANDERSON, E. C., FOGGIN, C. M., FERRIS, N. P. \& KNOWLES, N. J. (1994) Natural transmission of foot-andmouth disease virus from African buffalo (Syncerus caffer) to cattle in a wildlife area of Zimbabwe. The Veterinary Record, 134 230-232.

DE BOER, C. J. \& BACHRACH, H. L. (1961) The Multiplication of Foot-and-Mouth Disease Virus in Trypsinized Calf Kidney and Tongue Cells and Its Use As Immunizing and Complement-Fixing Antigens. The Journal of Immunology, 86282.

DURAND, S., MURPHY, C., ZHANG, Z. \& ALEXANDERSEN, S. (2008) Epithelial Distribution and Replication of Foot-and-Mouth Disease Virus RNA in Infected Pigs. Journal of Comparative Pathology, 139 86-96.

ESCARMis, C., CARrillo, E. C., FERrer, M., ARriaZA, J. F. G., LOPEZ, N., TAMi, C., VERDAGUER, N., DOMINGO, E. \& FRANZE-FERNANDEZ, M. T. (1998) Rapid Selection in Modified BHK-21 Cells of a Foot-and-Mouth Disease Virus Variant Showing Alterations in Cell Tropism. Journal of Virology, 72, 10171-10179.

FIELDS, B. N., KNIPE, D. M., HOWLEY, P. M. \& GRIFFIN, D. E. (2007) Fields' Virology (5th ed), Lippincott Williams \& Wilkins.

GARCIA-ARRIAZA, J., MANRUBIA, S. C., TOJA, M., DOMINGO, E. \& ESCARMIS, C. (2004)

Evolutionary Transition toward Defective RNAs That Are Infectious by Complementation. Journal of Virology, 78, 11678-11685.

GIBBS, S. \& PONEC, M. (2000) Intrinsic regulation of differentiation markers in human epidermis, hard palate and buccal mucosa. Archives of Oral Biology, 45 149-158. 
GIRARD, S., COUDERC, T., DESTOMBES, J., THIESSON, D., DELPEYROUX, F. \& BLONDEL, B. 1999. Poliovirus induces apoptosis in the mouse central nervous system. The Journal of Virology $\mathbf{7 3}$ 6066 .

GRUBMAN, M. J. \& BAXT, B. (2004) Foot-and-Mouth Disease. Clinical Microbiology Reviews, 17 465-493.

HOHL, D., OLANO, B. R., VIRAGH, P. A., HUBER, M., DETRISAC, C. J., SCHNYDER, U. W. \& ROOP, D. R. (1993) Expression patterns of loricrin in various species and tissues. Differentiation, $\mathbf{5 4}$ 25-34.

HOWEY, R., QUAN, M., SAVILL, N. J., MATTHEWS, L., ALEXANDERSEN, S. \& WOOLHOUSE, M. E. J. (2008) Effect of the Initial Dose of Foot-and-Mouth Disease Virus on Early Viral Dynamics within Pigs. Journal of the Royal Society Interface (doi:10.1098/rsif.2008.0434)

JIN, H., XIAO, C., ZHAO, G., DU, X., YU, Y., KANG, Y. \& WANG, B. 2007. Induction of immature dendritic cell apoptosis by foot and mouth disease virus is an integrin receptor mediated event before viral infection. Journal of Cellular Biochemistry 102 980-991.

KEELING, M. J. (2005) Models of foot-and-mouth disease. Proceedings of the Royal Society BBiological Sciences, 272 1195-1202.

KITCHInG, P., HAMMOND, J., JEGGO, M., CHARLESTON, B., PATON, D., RODRIGUEZ, L. \& HECKERT, R. (2007) Global FMD control-Is it an option? Vaccine, 25 5660-5664.

KOCH, G. \& KOCH, F. (1985) Molecular Biology of Poliovirus, Springer.

KRAKAUER, D. C. \& KOMAROVA, N. L. (2003) Levels of selection in positive-strand virus dynamics. Journal of Evolutionary Biology, 16 64-73.

MONAGHAN P., COOK H., HAWES P., SIMPSON J. \& TOMLEY F. (2003) High-pressure freezing in the study of animal pathogens. Journal of Microscopy 212 62-70.

MONAGHAN, P., COOK, H., JACKSON, T., RYAN, M. \& WILEMAN, T. (2004) The ultrastructure of the developing replication site in foot-and-mouth disease virus-infected BHK-38 cells. J General Virology 85 933-46.

MONAGHAN, P., GOLD, S., SIMPSON, J., ZHANG, Z., WEINRAB, P. H., VIOLETTE, S. M., ALEXANDERSEN, S. \& JACKSON, T. (2005) The avb6 integrin receptor for FMDV is expressed constitutively on the epithelial cells targeted in cattle. Journal of General Virology 86 2769-2780.

MOORE, J.V. (1987) Death of cells and necrosis in tumours. In Perspectives in mammalian cell death, ed. C.S. Potten, Oxford University Press.

PARIDA, S., COX, S. J., REID, S. M., HAMBLIN, P., BARNETT, P. V., INOUE, T., ANDERSON, J. \& PATON, D. J. (2005) The application of new techniques to the improved detection of persistently infected cattle after vaccination and contact exposure to foot-and-mouth disease. Vaccine 23 5186-95.

PENG, J., LIANG, S. \& LIANG, C. 2004. VP1 of foot-and-mouth disease virus induces apoptosis via the Akt signaling pathway. Journal of Biological Chemistry 27952168.

PENGYAN, W., YAN, R., ZHIRU, G. \& CHUANGFU, C. (2008) Inhibition of foot-and-mouth disease virus replication in-vitro and in-vivo by small interfering RNA. Virology Journal, 5, 86.

POTTEN, C. S., BOOTH, D., CRAGG, N. J., TUDOR, G. L., O'SHEA, J. A., APPLETON, D., BARTHEL, D., GERIKE, T. G., MEINEKE, F. A. \& LOEFFLER, M. (2002a) Cell kinetic studies in the murine ventral tongue epithelium: thymidine metabolism studies and circadian rhythm determination. Cell Proliferation 35 1-15.

PotTen, C. S., BoOth, D., CRAGG, N. J., TUdor, G. L., O'SheA, J. A., BOOTH, C., MEINEKE, F. A., BARTHEL, D. \& LOEFFLER, M. (2002b). Cell kinetic studies in the murine ventral tongue epithelium: mucositis induced by radiation and its protection by pretreatment with keratinocyte growth factor(KGF). Cell Proliferation 35 32-47.

QUAN, M. (2005) Quantitative dynamics of Foot-and-Mouth Disease Virus Infection in Pigs. University of Edinburgh.

ROWAT, J. S. \& SQUIER, C. A. (1986) Rates of epithelial cell proliferation in the oral mucosa and skin of the tamarin monkey (Saguinus fuscicollis). Journal of Dental Research, 65 1326-1331.

SAIZ, M., NUNEZ, J. I., JIMENEZ-CLAVERO, M. A., BARANOWSKI, E. \& SOBRINO, F. (2002) Foot-and-mouth disease virus: biology and prospects for disease control. Microbes and Infection, 4 1183-1192.

SOBRINO, F. \& DOMINGO, E. (2004) Foot and mouth disease: current perspectives. Foot and Mouth Disease: Current Perspectives.

THORNE, H. V. (1962) Kinetics of cell infection and penetration by the virus of foot-and-mouth disease. Journal of Bacteriology, 84929. 
WINNING T.A., TOWNSEND G.C. (2000) Oral mucosal embryology and histology. Clinics in Dermatology 18 499-511.

ZHANG, Z. \& ALEXANDERSEN, S. (2004) Quantitative analysis of foot-and-mouth disease virus RNA loads in bovine tissues: implications for the site of viral persistence. Journal of General Virology, 852567.

ZHANG, Z. D. \& KITCHING, R. P. (2001) The Localization of Persistent Foot and Mouth Disease Virus in the Epithelial Cells of the Soft Palate and Pharynx. Journal of Comparative Pathology, 124 89-94. 